\title{
The Impact of Using a Survey Framework in Leadership Education: Is More Better?
}

\author{
Steven M. Samuels, Ph.D. \\ Professor \\ Department of Behavioral Sciences \& Leadership \\ United States Air Force Academy \\ Colorado Springs, CO \\ steven.samuels@usafa.edu \\ Douglas R. Lindsay, Ph.D. \\ Associate Professor \\ Department of Behavioral Sciences \& Leadership \\ United States Air Force Academy \\ Colorado Springs, CO \\ douglas.lindsay@usafa.edu \\ Daniel J. Watola, Ph.D. \\ Assistant Professor \\ Department of Behavioral Sciences \& Leadership \\ United States Air Force Academy \\ Colorado Springs, CO \\ daniel.watola@usafa.edu \\ James C. Walliser \\ Instructor \\ Department of Behavioral Sciences \& Leadership \\ United States Air Force Academy \\ Colorado Springs, CO \\ robert.reimer@usafa.edu \\ Robert D. Reimer \\ Instructor \\ Department of Behavioral Sciences \& Leadership \\ United States Air Force Academy \\ Colorado Springs, CO \\ james.walliser@usafa.edu
}

"It is almost a cliché of the leadership literature that a single definition of leadership is lacking." (Bennis, 2007) 
This quotation by Bennis is bantered about quite often by leadership researchers and practitioners as a call to arms to get our proverbial act together and find some common ground on what we are talking about when we refer to this construct called leadership. On many levels it makes sense to have an agreed upon definition or set of parameters when we refer to leadership. Yet, a recent trend among leadership researchers is to further the proliferation of leadership types that are continually showing up in the literature. Even a cursory view of the leadership literature shows dozens of different forms of leadership (e.g., authentic, servant, shared). While it is clear that certain contexts elicit or make more salient certain leader behaviors, does that necessarily mean that we should continue categorizing leadership based on the context in which it is enacted?

We do not think so. The modern environment in which leaders operate is complex, dynamic, and ambiguous. In such contexts it is better to have a full toolbox of leadership approaches. Leaders can then select the right tool or combination of tools for the occasion, rather than rely on a single tool for all occasions. Therefore, we suggest that education should focus on better preparing our leaders using a broad survey framework instead of a single leadership approach as the only basis for their development.

This brings up the issue of how we should prepare our future leaders. A quick answer would generally consist of such things as education, reflection, training, and application. While these are all important, and certainly have their place in leader development, how one goes about delivering these to the individual is much more complicated. Jenkins (2012) indicated that there are over 1500 leadership studies programs in existence. If one were to look at actual courses on leadership, even this large number would swell considerably.

While Jenkins (2012) cogently explained the different pedagogical techniques that exist in leadership classes today, we wondered about the content covered through these techniques. For example, were they focused on broad over-arching theories of leadership such as the Full Range Model of Leadership (Sosik \& Jung, 2010) or more specific theories such as crisis leadership? This is not a trivial distinction. As educators should we focus on broad-based survey courses where students get exposed to many different types of leadership or should we focus on a particular type of leadership that we want them to apply? This may not be as critical for leadership programs that offer many classes, as students can learn various aspects of leadership through subsequent semesters. However, for those numerous students that only take a single leadership course, this becomes crucial. Certainly, this is not a new debate; this is a situation that plagues many different academic disciplines. 
In addition to optional leadership courses primarily for those who choose to major in the topic, the United States Air Force Academy offers a core leadership course required for all students. This single semester course focuses on a behavioral sciences approach to leadership with concomitant application opportunities. The underlying premise is that through exposure to the leadership literature and helping create connections in their occupational and personal lives, students will be better prepared to interpret future leadership situations. Our wide ranging survey framework covered six different areas - Contingency approaches, FullRange Leadership Development Model, Skill/Competency-based approaches, Social Interaction approaches, Styles of leadership, and Trait-based approaches.

Given such a broad focus, we constantly wonder if we should instead use our semester to focus on one particular theory of leadership that students might be able to better master and utilize (e.g., Full Range Leadership Model). To address the issue, we decided to collect data to discover which approach resonated most among the students.

For their final course paper students identified and discussed the two approaches they decided were best, that is those two they found contributed most to their evolving personal theory of effective leadership. Students also identified and discussed one approach they decided was the worst or in other words the one that contributed least to their evolving personal theory of effective leadership. The results from 163 students enrolled in courses taught by five faculty members can be seen in Figure 1. The result are ordered from highest to lowest in terms of the approach students thought contributed the most (i.e., best) to their leadership development.

Figure 1

Percentage of students' best and worst leadership approaches $\mathrm{N}=163$ 


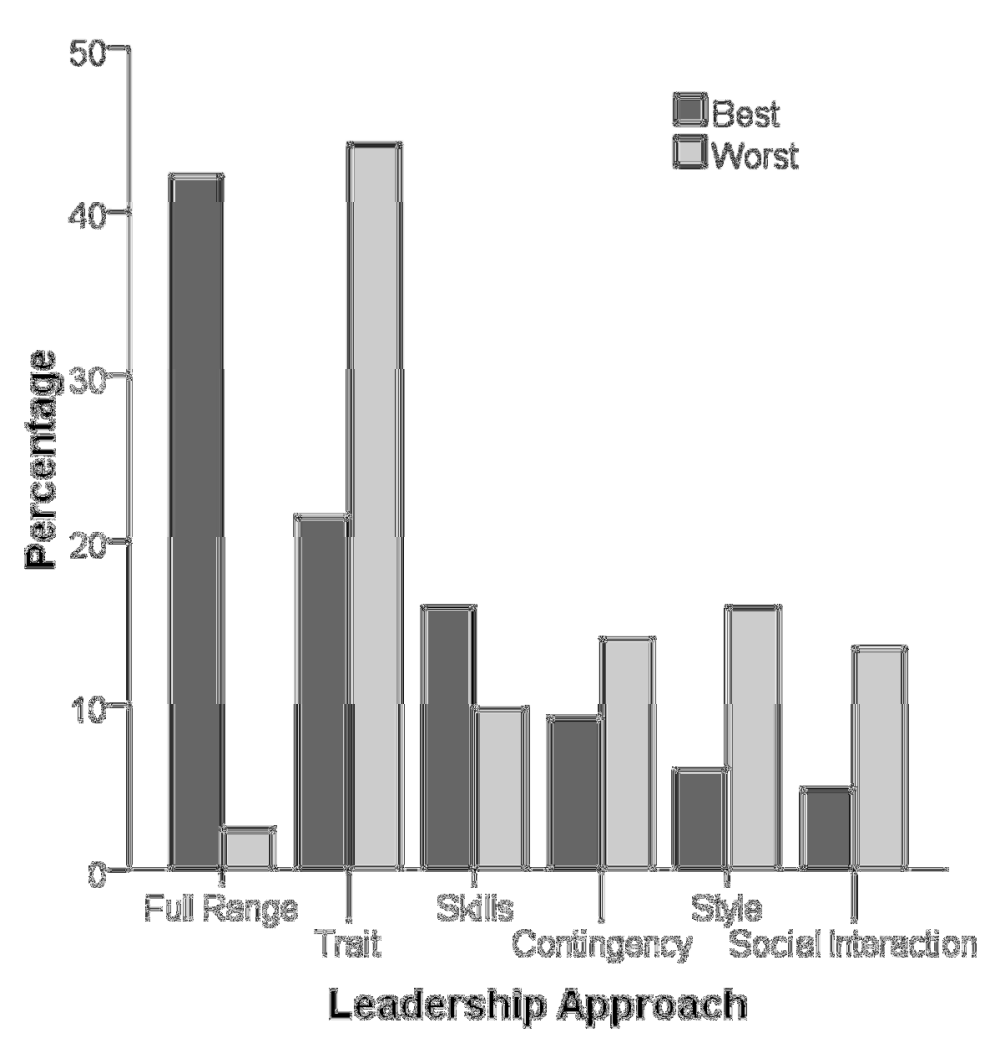

It is first interesting to note that there are substantial votes for both the best and worst for each approach, except perhaps for the worst Full Range Leadership with only $2.5 \%$ of student choices. Also, the relationship between the best and worst choices is not clear. That is, if there truly was a best and worst overall approach, we would expect to see a pattern whereby the best approach would have the fewest amount of worst votes as demonstrated by the pattern for Full Range Leadership and vice versa. However, aside from Full Range Leadership, there does not appear to be a pattern for any other approach.

Full Range Leadership was by far the favorite approach, chosen as the best on $42.3 \%$ of the papers, while Trait theory was a distant second with barely half as many choices $(21.5 \%)$. At the same time, Trait theory was by far thought to be the worst on $44.2 \%$, while Style was a distant second with roughly one-third as many choices (16.0\%).

The pattern on total frequency of chosen responses (i.e., all the times an approach was mentioned regardless) was also of interest. Trait (32.8\%) was by far mentioned the most, followed by Full Range Leadership (22.4\%) while Social Interaction (9.2\%) and Style (11.0\%) were chosen the least. 
So, what does all this mean? It may indicate that each of the approaches resonated with some of the students: each was valued and thought to contribute most to their development. This seems to suggest that each of the approaches had some student connection, which indicates initial support for the survey approach to the course. Opinions about the different approaches were very much driven by each individual student, so the variety of approaches created a greater variety of student involvement and hopefully student learning.

Even though all approaches were chosen, it is interesting to note that the Full Range Leadership was chosen best by almost half of the students. This may be due to students seeing links in it to several of the other approaches (e.g., Full Range's Individualized Consideration being similar to Social Interaction's Leader-Member Exchange Theory (LMX); Inspirational Motivation linking to Trait theory's extraversion). Perhaps more interestingly, only four students thought it was the worst approach. On the other hand, while Trait theory was heavily disliked by nearly half the students, it was also the second most popular for the best approach. This could be due to students' beliefs and feelings about the inherent qualities of leadership, which Trait theory best supports. It also could be that Trait theory is perhaps the easiest to understand, and thus potentially the easiest to write about. Yet, a similar comment about simplicity could be made for the Skills development which was rarely picked in either category (12.9\% overall).

These data clearly suggest that a broad survey approach can encourage engagement with the material from students with different leadership perspectives. Such a leadership course draws strength from a diversity of approaches, allowing students to gravitate toward the approach that resonates with them. Thus, they begin to shape their own leadership with the lenses they choose to wear. Additionally, students may realize that there are other approaches, other lenses that other leaders may be choosing. Better students may also realize that to improve their own leadership, they may have to embrace approaches that they are not comfortable applying. The best students may ultimately realize while they gravitate to one or two approaches, all approaches can and should contribute to developing leaders. There is no single correct approach.

One way multiple approaches can inform each other is when they interact and provide greater insight to the leadership dynamic. For example, it may be of limited value to use Inspirational Motivation if you do not understand a Contingency approach like Situational Leadership Theory and your subordinates are enthusiastic beginners who need hands-on attention. Additionally, two congruent approaches can add strength to each other, informing each other in subtle, yet significant ways. For example, while Individualized Consideration is 
extremely important, it can be augmented by the greater specifics discussed in LMX theory.

However, the broad survey concept can create challenges for some students. Some, perhaps especially those not versed in the social sciences and humanities, may find a no clear solution answer to be frustrating. These students appeared to be confused by the number of approaches covered, and their overlap and divergence. They may have reactively rejected the science that leads to this outcome and regressed to an it is all common sense place, or worse, you are born with it or you are not view point.

While this general approach to leadership education in this course seemed to have a positive impact on the students, one must be careful to generalize the results since this was applied to a single course versus an entire program. It is important to note that within our Behavioral Sciences Department, a Leadership and Organizations track includes an advanced course that takes the opposite philosophy: that is, an in-depth look at the Full Range Leadership Model which focuses on transformational leadership. Our belief is that once students who are interested in studying leadership have had the broad survey course, a detailed focus is absolutely appropriate.

In summary, while it is clearly important to understand effective pedagogies when teaching a leadership course, it is equally important to consider the framework that will be used. Such a framework will have a direct impact on what students take away from the course, and thus what students will most likely apply in their leadership experiences. Of course, this is not an experimental design and we have not been able to isolate causality or every potential variable. Further research should look into issues such as primacy versus recency, complexity of approaches, students' pre-existing positions, and other related issues. By using a broad framework of approaches to teach leadership, students can benefit by finding those approaches that best align with their own views of how they themselves lead. And capturing students' imagination certainly makes it more likely they will take the extra step of bringing the knowledge from the classroom into their lives.

NOTE: The views expressed in this article are those of the authors. They do not necessarily reflect those of the United States Air Force Academy or the Department of Defense. 


\section{References}

Bennis, W. (2007). The challenges of leadership in the modern world. American Psychologist, 62, 2-5.

Jenkins, D. M. (2012). Exploring signature pedagogies in undergraduate leadership education. Journal of Leadership Education, 11, 1-27.

Sosik, J. J., \& Jung, D. I. (2010). Full range leadership development. New York: Routledge. 


\section{Author Biographies}

Steven M. Samuels, Ph.D., is a Professor in the Department of Behavioral Sciences and Leadership at the United States Air Force Academy, Colorado Springs, Colorado. He received his B.A. in Philosophy and Psychology from Brandeis University and his doctorate in Social Psychology from Stanford University. His research focuses on applying social psychology, primarily in the areas of ethical behavior, pedagogy, and leadership, as well as investigating diversity and social justice. In addition to numerous publications and presentations in these areas, he is regularly invited to give lectures at organizations around the United States.

Douglas R. Lindsay, Ph.D., United States Air Force, is the Deputy Department Head and an Associate Professor for the Department of Behavioral Sciences and Leadership at the United States Air Force Academy, Colorado Springs, Colorado. He received his doctorate degree in Industrial/Organizational Psychology from Pennsylvania State University. Dr. Lindsay's research interests are in the areas of leadership, leadership development, leader-follower dynamics, and followership. He has over 50 publications and presentations on these topics. He has been published in journals such as the Journal of Leadership Education, Military Psychology, International Journal of Training and Development, and Human Resource Development International. He has presented at such venues as the American Psychological Association, American Psychological Society, Society for Industrial \& Organizational Psychology, International Military Testing Association, and International Leadership Association.

Daniel J. Watola, Ph.D., United States Air Force, is an Assistant Professor and Director of Academics in the Department of Behavioral Sciences and Leadership, United States Air Force Academy, Colorado Springs, Colorado. He graduated from the United States Air Force Academy with a B.S. degree in Human Factors Engineering and obtained Master of Arts and Doctor of Philosophy degrees in Industrial and Organizational Psychology. He has served in several science and engineering positions throughout the Air Force, including flight test engineer for the Northrup-Grumman B-2A Spirit, Occupational Analyst, and Research Laboratory Division Chief. Dr. Watola has also served as a Staff Officer and Executive Officer in Air Education and Training Command's Directorate of Operations. Prior to his current assignment, he was the Deputy Commander of Detachment 5, Air Force Research Laboratory at Brooks City-Base, Texas.

James C. Walliser, United States Air Force, is the Personnel Officer and an Instructor for the Department of Behavioral Sciences and Leadership at the United States Air Force Academy, Colorado Springs, Colorado. He received his 
master's degree in Human Systems Integration from the Naval Postgraduate School. James' research interests are in the areas of leadership, decision making, trust, and automation. He has published in Aviation, Space, and Environmental Medicine and presented his work at the Human Factors and Ergonomics Society and the Society of Flight Test Engineers.

Robert D. Reimer, United States Air Force, is an Instructor in the Department of Behavioral Sciences and Leadership at the United States Air Force Academy, Colorado Springs, Colorado. He received a bachelor's degree in Electrical Engineering from the United States Air Force. In addition, Robert has earned two master's degrees - Aeronautical Science and Safety from Embry-Riddle Aeronautical University and Human Services and Educational Leadership from the University of Colorado at Colorado Springs. As a Major in the Air Force he has served in many capacities from pilot to commander. His research interests are in the areas of motivation and performance appraisal. 